\section{Management of prosthetic valve thrombosis concomitant with coronary embolism}

\author{
To the Editor,
}

We have recently read with great interest the article by Olcay (1) published in Anatol J Cardiol 2018; 20: 365-7. We appreciate the author for his report describing the concomitant left main coronary artery and mitral prosthetic valve thrombosis (PVT) treatment. On the other hand, we believe that there are several major drawbacks that need to be addressed.

Coronary embolism (CE) is a rare cause of acute coronary syndrome (ACS) in patients with prosthetic heart valves. Information regarding ACS in patients with prosthetic heart valves is scarce and based mainly on case reports and limited number of clinical trials $(2,3)$. We agree with the authors that thrombolytic therapy (TT) provides the advantage of widespread availability and easier administration than surgery (4). However, low-dose and ultraslow fibrinolytic therapy $(25 \mathrm{mg} / 25 \mathrm{~h}$ ) in a patient with cardiogenic shock may not be an effective option for urgent treatment (5). Recently, Yesin et al. (3) reported that TT with low-dose and slow infusion of tissue plasminogen activator (tPA) $(25 \mathrm{mg} / 6$ h) has proven its efficacy and safety in patients with concomitant CE and PVT. In such cases, low-dose and slow infusion TT may be preferred to ultraslow infusion as a bailout treatment strategy when surgical support is insufficient.

We totally disagree with the authors about simultaneous heparin infusion during TT administration. The primary goal of reducing tPA dose and infusion rate was to reduce major bleeding complications. Other entities that we have proposed to reduce bleeding in the TROIA and the ultraslow PROMETEE Trials were omitting bolus tPA dose and avoiding concomitant anticoagulant use $(5,6)$. Recently, we have described how to perform and manage low-dose and slow/ultraslow tPA infusion regimens in patients with PVT (4). In this case report, there are no data regarding the preparation and providing the biological stability of reconstituted solution during a 24-hour infusion. In addition, after the first session of TT, the resolution of the stuck leaflet was visualized by transesophageal echocardiography (TEE), and the author decided to perform one more session of TT. There were no data regarding the size of the residual thrombus in the case report. Was there an indication $\left(>10 \mathrm{~mm}\right.$ or $\left.0.8 \mathrm{~cm}^{2}\right)$ to continue the TT for a non-obstructive PVT? Cine fluoroscopy (CF) is a lowcost, noninvasive imaging technique, which is readily available in most centers and can be performed rapidly, particularly in unstable patients, for detecting stuck valves. Although the role of CF has declined since the introduction of TEE, it still serves as a complementary method to TEE in the evaluation of PVT and guiding $\mathrm{TT}(4,7)$.

Real-time three-dimensional (RT-3D) TEE has emerged as an important clinical tool in the assessment of PVT for more than 10 years. RT-3D TEE has higher spatial resolution, resulting in images with unparalleled anatomical detail when compared with two-dimensional (2D) imaging. The detection of non-obstructive PVT can be challenging, particularly when Doppler parameters are within normal limits, and clinical findings are subtle. Hence, non-obstructive PVT can be even missed with 2D TEE. The diagnostic accuracy for detecting PVT was improved after the introduction of RT-3D TEE, especially for those on mitral position (7).

In conclusion, low-dose and slow infusion TT would be a better treatment strategy in such patients with concomitant CE and PVT except cardiogenic shock.

(D) Macit Kalçık, AD Ahmet Güner', (D) Sabahattin Gündüz²,
(D) Mehmet Özkan'
Department of Cardiology, Faculty of Medicine, Hitit University;
Çorum-Turkey
'Department of Cardiology, Kartal Koşuyolu Heart Training and
Research Hopital; İstanbul-Turkey
'Department of Cardiology, VM Medikal Park Pendik Hospital;
İstanbul-Turkey

\section{References}

1. Olcay A. Concomitant left main coronary artery and prosthetic mitral valve thrombosis treatment. Anatol J Cardiol 2018; 20: 365-7.

2. Guner A, Kılıcgedik A, Kalçık M, Ozkan M. ST-segment elevation myocardial infarction possibly caused by thromboembolism from left atrial appendage thrombus after incomplete surgical ligation. Echocardiography 2018; 35: 1889-92. [CrossRef]

3. Yesin $M$, Karakoyun $S$, Kalçık M, Gürsoy M0, Gündüz S, Astarcıoğlu $M A$, et al. Status of the Epicardial Coronary Arteries in Non-ST Elevation Acute Coronary Syndrome in Patients with Mechanical Prosthetic Heart Valves (from the TROIA-ACS Trial). Am J Cardiol 2018; 122: 638-44. [CrossRef]

4. Guner A, Kalcik M, Gursoy M0, Gunduz S, Ozkan M. How to perform and manage low-dose and slow/ultra-slow tissue type plasminogen activator infusion regimens in patients with prosthetic valve thrombosis. J Thromb Thrombolysis 2018; 46: 399-402. [CrossRef]

5. Özkan M, Gündüz $S$, Gürsoy $0 M$, Karakoyun $S$, Astarcıŏlu MA, Kalçık M, et al. Ultraslow thrombolytic therapy: A novel strategy in the management of PROsthetic MEchanical valve Thrombosis and the prEdictors of outcomE: The Ultra-slow PROMETEE trial. Am Heart J 2015; 170: 409-18. [CrossRef]

6. Özkan M, Gündüz S, Biteker M, Astarcioglu MA, Çevik C, Kaynak $E$, et al. Comparison of different TEE-guided thrombolytic regimens for prosthetic valve thrombosis: the TROIA trial. JACC Cardiovasc Imaging 2013; 6: 206-16. [CrossRef]

7. Gürsoy $M 0$, Kalçık $M$, Yesin $M$, Karakoyun $S$, Bayam $E$, Gündüz $S$, et al. A global perspective on mechanical prosthetic heart valve thrombosis: Diagnostic and therapeutic challenges. Anatol J Cardiol 2016; 16: 980-9. 
Address for Correspondence: Dr. Ahmet Güner, İstanbul Kartal Koşuyolu Yüksek İhtisas Eğitim ve Araştırma Hastanesi,

Kardiyoloji Kliniği;

Denizer Caddesi No:2 Kartal,

İstanbul-Türkiye

Phone: +902165001500

E-mail: ahmetguner489@gmail.com

(C) Copyright 2019 by Turkish Society of Cardiology - Available online

at www.anatoljcardiol.com

DOI:10.14744/AnatolJCardiol.2018.88288

\section{Author’s Reply}

To the Editor,

I thank the authors for their interest. The first title of the case report was "Concomitant left main coronary artery and prosthetic mitral valve thrombosis treatment: Improvisation is a must!" to emphasize the uncertainty and need for versatility while treating these patients. There were two patients treated by percutaneous coronary intervention in Yesin et al.'s (1) paper, but there is no detail about the amount and quality of coronary thrombotic material. I think that there are two kinds of thrombotic coronary materials in these patients: easily dispersible and lysable and denser, bulkier coronary thrombotic material. I am not aware of any autopsy or thrombus aspiration study in such patients characterizing thrombus qualities, and Yesin et al. (1) study cannot be accepted as the last verdict in these patients due to limitation in describing coronary thrombus quality and amount. Our case fundamentally differs from their patient group by left main coronary artery occlusion and urgent need for terminating coronary ischemia. In Yesin's study, only $19 \%$ of the patients were receiving aspirin, and none were on clopidogrel on admission that reduced the bleeding rate in their protocol. I retrospectively think that low-dose and ultraslow fibrinolytic therapy $(25 \mathrm{mg} / 25 \mathrm{~h}$ ) was safer in our patient due to aspirin and clopidogrel treatment necessitated by stent implantation and suggested $25 \mathrm{mg} / 6 \mathrm{~h}$ protocol would increase bleeding risk. Heparin infusion was necessitated due to intra-aortic balloon pump (IABP) use in the follow-up. Our patient is also different from the TROIA and PROMETEE patient groups that did not include any patient with $\operatorname{IABP}(2,3)$. As a result, it is very difficult for authors to say "total disagreement on heparin use" by referencing the TROIA and PROMETEE trials because both were not enrolling any patient on IABP. Necessary precautions were taken for tPA stability during a 24-hour infusion. We do not know the thrombus size before the $2^{\text {nd }}$ episode of tPA infusion because TEE was not performed again due to the general condition of the patient and good transthoracic image quality showing stuck mitral leaflet.

In conclusion, it is very difficult for authors to claim low-dose and slow infusion $T T$ to be a better treatment strategy in our patient because their referenced studies did not include any patient on IABP.

\footnotetext{
(D) Ayhan Olcay

Department of Cardiology, Faculty of Medicine, İstanbul Aydın University; İstanbul-Turkey
}

\section{References}

1. Yesin $M$, Karakoyun $S$, Kalçık $M$, Gürsoy MO, Gündüz $S$, Astarcıoğlu $M A$, et al. Status of the Epicardial Coronary Arteries in Non-ST Elevation Acute Coronary Syndrome in Patients with Mechanical Prosthetic Heart Valves (from the TROIA-ACS Trial). Am J Cardiol 2018; 122: 638-44.

2. Özkan $M$, Gündüz $S$, Gürsoy $O M$, Karakoyun $S$, Astarcıoğlu $M A$, Kalçık $\mathrm{M}$, et al. Ultraslow thrombolytic therapy: A novel strategy in the management of PROsthetic MEchanical valve Thrombosis and the prEdictors of outcomE: The Ultra-slow PROMETEE trial. Am Heart J 2015; 170: 409-18.

3. Özkan M, Gündüz S, Biteker M, Astarcioglu MA, Çevik C, Kaynak $E$, et al. Comparison of different TEE-guided thrombolytic regimens for prosthetic valve thrombosis: the TROIA trial. JACC Cardiovasc Imaging 2013; 6: 206-16.

Address for Correspondence: Dr. Ayhan Olcay,

İstanbul Aydın Üniversitesi Tıp Fakültesi,

Kardiyoloji Anabilim Dalı,

İstanbul-Türkiye

Phone: +90 5325272207

E-mail:drayhanolcay@gmail.com

(C) Copyright 2019 by Turkish Society of Cardiology - Available online

at www. anatoljcardiol.com

\section{Factors associated with periprocedural myocardial infarction}

To the Editor,

We have read with great interest the article by Yao et al. (1) on the association between baseline CRP levels and the occurrence of periprocedural myocardial infarction. It is reported that higher baseline CRP levels are associated with increased periprocedural myocardial infarction incidence. Patient medications, except statins and antiplatelets, were not assessed, and this was reported as a limitation (1).

Smoking status is an important issue because it has several adverse effects on endothelial functions. Moreover, smoking results in the induction of CYP450 enzyme system and in the increased metabolism of clopidogrel (2). Therefore, smoking decreases the antiplatelet effects of clopidogrel, and it may play a significant role in periprocedural myocardial infarction.

Clopidogrel is an effective P2Y12 inhibitor that prevents stent thrombosis and restenosis; however, it does not exhibit a same effect in all patients. Certain patients are resistant to antiplatelet drugs, and there exists a risk of major adverse cardiovascular events among these patients. High-on treatment platelet reactivity (HPR) defines inadequate antiplatelet response in patients undergoing antiplatelet therapy with optimal dose. Patients with HPR are prone to periprocedural stent thrombosis and restenosis. Therefore, such patients should be identified using platelet 